\title{
Contributions of Fisheries for Food and Nutrition Security: A Review with Ethiopian Contexts
}

\author{
Derese Tamiru Desta ${ }^{1} \quad$ Teshale Darebo ${ }^{2}$ \\ 1.School of Nutrition, Food Science and Technology, Hawassa University, P.O. Box 05, Hawassa \\ 2. Department of Public Health, Mizan Tepi University, Ethiopia
}

\begin{abstract}
In Ethiopia, mainly fish productions are from Great Rift Valley lakes and in some other northern parts of the country. Despite the potential of fish production its fish consumption is insignificant and found to play little role in the households' livelihood. The demand for fish in the country is increasing; however, the supply side is not increasing with large opportunities to produce. For The consumption pattern and demand is increasing. The total fish production of the country accounts less than 1 percent of total production in Sub-Saharan African countries. Therefore with a little contribution for food and nutrition security the fishery sector has challenges related to existing climate changes, mismanagement fishery resources, lack of timely policies and institution and other technical backups related to loose rules and regulations. There are numerous explanations ascribing to the low and poor production due to inappropriate and not advancing fishing methods, economic disabilities related to infrastructures like preservation technologies. The absence of appropriate managements has been affecting the utilization of fishery resources. Thus future works has to give due attentions to exploit the fish production potentials and enhance the contributions to food and nutrition security.
\end{abstract}

DOI: $10.7176 / \mathrm{FSQM} / 108-04$

Publication date:May $31^{\text {st }} 2021$

\section{Introduction}

In the post 2015 Malnutrition overwhelmingly threatening the entire world sustainable developments. Every country and one in three people are affected (WHO, 2015m). In more than half of the countries are affected by more than a single type of malnutrition (IFPRI, 2014a). The multiple malnutrition; under nutrition, micronutrient deficiency and over nutrition has been raising the economic and social costs. This malnutrition's may manifest at household and individuals with changing food system arena. Even malnutrition is a problem still existing as a policy challenges due to its complex, dynamicity and multidimensional (FAO, 2013). The sub-Saharan African countries are usually heated by chronic food insecurity as there is high population growth, natural resource dependency and climate (UNDP, 2010). The challenges are also causes under-nutrition in these poorest nations and still the world at large particularly the women and children. The signs of under nutrition including like stunting, wasting, mortality and morbidities has been given substantial attentions. Ending hunger and reducing under nutrition has therefore become a key objective of the Sustainable Development Goals (SDGs).

It is been believed that the animal source foods are very rich in macro and micro nutrients and hence their consumption has been promoted through food-based approaches as one of the ways to combat micronutrient deficiencies. However due to the limited availability and affordability usually it's not possible for the poor households to consume (Pachón et al., 2007). In this regards, fish might be affordable and available to be consumed in the developing countries. Even the fish production sector is very growing and more households are depending on it (Speedy, 2003; Ahmed and Lorica, 2002). Therefore, interventions intended to increase the fish intake has been implemented in these countries (Kawarazuka, 2010). Small-scale fisheries and aquaculture have been recognized as important opportunities for enhancing household food security.

In Ethiopia, fish supply is in most cases comes from the major lakes and rivers. Till to date despite the country's huge aquaculture potential, the contribution of aquaculture towards food security is insignificant (MoARD, 2008). Hence, there has to be more emphasis to enhance food production including fish for the livelihood of the vulnerable population. For instance per capita consumption of fish is very low in Ethiopia. There is steady growth in demand reflecting population increase, rising incomes and a shift in preferences. The main areas of fish consumption are mainly towns and close to the main production areas of major lakes including. Aquaculture in addition to others in the rural parts is one of the key nutrition sensitive interventions recently promoted as the country has huge aquaculture potentials. However, with the existing interventions and activities of fishery and aquaculture evidences showing the exact contributions of fishery and aquaculture are limited in Ethiopia. Therefore the current review is to state the existing contributions for food and nutrition security as well as the gaps in Ethiopia.

\section{Overview of Fishery and Aquaculture as a means of addressing Food and Nutrition Security}

Globally the aquaculture production has been growing and projected to grow. Food and Agriculture Organization reported that out of the total tons of fish consumed in the world every year, almost half is produced in a 
controlled environment, whereas the remaining half is harvested from the wild. It is growing, increasing and rising in almost all regions of the world, except in Sub- Saharan Africa (FAO, 2012). The fish considered and a rich source of macro and micronutrients represents less in the sub Saharan African countries and other developing countries.

Fish is nutritionally important in many African countries as well as in Asia and Oceania. There are 30 countries who meet this criterion, including 22 countries which were officially referred to as low-income food-deficit countries (LIFDC) in 2009 (FAO, 2009 b). In other words, a large majority (73\%) of the countries where fish is an important source of animal protein are poor and food deficient countries. In many low-income countries with water and fisheries resources, fish is important for livelihoods, income and as food for the rural poor who suffer disproportionately from under nutrition, including micronutrient deficiencies (Thompson and Subasinghe, 2011). For these population groups, fish is by far the most regularly consumed animal-source and thus makes a valued contribution to the diversity of everyday diets, dominated by carbohydrate-rich staples. Fish can therefore be considered an unique animal-source, providing essential nutrients of high bioavailability which are found in limiting amounts in the diet. These nutrients include animal protein, essential fats, minerals and vitamins. Small fish, eaten whole or as fish products, e.g. dried fish are particularly rich in calcium and other micronutrients. In terms of protein, it is recognized that in low-income food-deficit (LIFD) countries the main sources of protein comes from plants such as rice, maize, or cassava (FAO, 2009). In addition, as pointed out by Kawarazuka (2010), in some conditions fish can be a far more efficient source of protein than any other food for the poor, due in particular to their accessibility, availability and digestibility. While the digestibility of foods derived from plants is very poor compared to those derived from animals, among the latter, fish is one of most affordable and accessible sources

The importance of fish as a source of animal protein and essential fatty acids is reasonably well documented. Recently studies suggest, however, that fish - and in particular small fish species - are rich in micronutrients (including calcium, iron and zinc and in vitamin A) (Kawarazuka, 2010). Plant foods, especially staples such as rice and maize, which contain low concentrations of lysine, have relatively limited levels of protein absorption as the amount absorbed is determined by the concentration of the least well represented essential amino acid ( WHO, 2007). In contrast, proteins from animal sources, such as fish, have more balanced concentrations of all the essential amino acids and their concentration of lysine is particularly high (USDA, 2005).

Availability, accessibility, cultural practices and personal preferences has been considered as the major factors for contributions for food and nutrition security of the households and individuals. Location and prices as well as the seasonality are also other factors for access for the households. Whereas at the individual level it also depends upon a person's physiological and health status and how fish is prepared, cooked and shared among household members. The persistent and speedy growth of aquaculture over the past 30 years has brought in $>40 \%$ of all fish now consumed being come from farming. Though aquaculture harvest progressively features in the diets of many Asians, it is much less deceptive among those living in Sub-Saharan Africa. The contribution of aquaculture to food and nutrition security is not only just an issue of where aquaculture occurs but also of what is being produced and how and whether the produce is as accessible as that from capture fisheries. The range of fish species produced by an increasingly globalized aquaculture industry differs from that derived from capture fisheries. Farmed fishes are also different in terms of their nutrient content, a result of the species being grown and of rearing methods. Farmed fish price affects access by poor consumers while the size at which fish is harvested influences both access and use (Beveridge et al., 2013).

The contributions of fisheries and aquaculture can be entertained by direct and indirect mechanisms. The direct mechanism is the contribution for the direct consumptions from the production. For instance, poor people in developing countries tend to depend essentially on carbohydrate-based diets for their nutritional intake. These are, however, relatively low in protein and micronutrients. In this context, fish can play a particularly important role in combating micronutrient deficiencies, as they contain high quality protein, essential fatty acids and also key micronutrients such as vitamin A, iron, calcium, zinc and iodine (Kawarazuka, 2010; Kawarazuka \& B'en'e, 2011). It is as a source of essential fatty acids and micronutrients, superior in both qualitative and quantitative terms to other animal-source foods, that may be of greatest importance in food and nutrition security terms.

On the other hand, studies published in the literature report an increase in household consumption of fish for those who invest in pond-based aquaculture or in integrated agriculture-aquaculture. Consuming fish produced by their own ponds is a way for households to directly improve nutritional status through aquaculture (Kawarazuka, 2010). In India, Kumar and Dey (2006) observed that the energy intake of households that own fish ponds was $10.9 \%$ higher than that of households with wage earners but without ponds, and that the undernourished population amongst the fish pond owners was 10\% lower than the control population. In the Dinajpur district of Bangladesh, it was shown that small fish species are important food items for low income households with fish ponds, especially in months when vegetables are not available or not affordable (Islam, 2007). In Malawi, Dey and his colleagues compared fish consumption between households with and without fish ponds. They observed that the frequency of fresh fish and dried fish consumption is higher in households with 
fish ponds (Dey et al. 2006).

To the opposite, in addition to direct contribution to dietary intake, fish is sold, contributing to household food security indirectly through increasing household income. This will in turn, can be utilized to purchase other food supplies, including lower cost staple foods (Béné et al., 2007; Aiga et al., 2009). It is one of livelihood strategies that have contributed much to people in developing countries. It is one of the vital strategies for the poor to achieve food, income and other social benefits (Manasi et al., 2009). The positive impact of fishery on household incomes was observed in several studies.

There are several studies confirming the contributions in Ethiopia and in the other regions. In Ethiopia, a study done by Gebremedhin and his colleagues (2013) done in Lake Tana show a significant income from fishery. It contributed $48 \%$ to the total annual income of the fishers. In Malawi, Dey and his colleagues found that the income of households owning fish ponds was 1.5 times higher than that of households without fish ponds (Dey et al., 2006). In Bangladesh, Jahan and colleagues found that the average gross income of households recently engaged in pond aquaculture with technical support and management grew $8.1 \% /$ year generating a return on family labour of $15.6 \%$ year. For poor rural households engaged in aquaculture or capture fisheries the surplus cash generated by selling fish is often used to buy food. Recent studies highlight the positive effects of household income from aquaculture in increasing consumption of staple foods (Jahan et al., 2009).

The contributions of fishery may be depicted in the UNICEF (1990) conceptual framework of malnutrition which was adopted from the UNICEF's malnutrition conceptual framework. It is further elaborated by Kawarazuka(2010) below in the figure 1. According to the conceptual framework the causes of malnutrition can be categorized into Immediate, Underlying and basic causes. Poor nutritional status results from underlying problems related to social institutions and mechanisms which give rise to poverty and inequality basic determinants) in a broader context. Household food security; maternal and child care; and health services and healthy environment, are three pillars of underlying determinants of nutritional status. Diversifying livelihoods to increase household income sources is a way of improving household food security. Although fish-related literature often does not include studies related to other pillars, child care, especially breast-feeding is an important factor to determine children's nutritional status. Access to health services and living environment is also an important factor as it determines the risk of diseases. Dietary intake is an immediate determinant of nutritional status. The typical diet of the poor is dominated by staple foods with small amounts of other plantsource foods such as vegetables and animal-source foods. Diversifying diet by adding animal-source foods, fruits and vegetables in their diets provides a variety of nutrients, contributing to improving nutritional status.

Disease is another determinant of nutritional status, and there is a direct correlation between these two factors. For example, an inadequate diet results in increasing the risk of diseases. Sick people require additional energy intake to fight disease, and at the same time, they have a poor appetite. Meanwhile in affected households, the labor productivity is reduced and extra money and time to care for the sick are needed. Consequently, diseases affect the nutritional status of not only individuals, but also other household members. In contrast, adequate dietary intake maintains the body's immunity and decreases the risk of diseases, contributing to minimizing extra costs and time for care and treatment, while optimizing labor productivity. Taking in mind this conceptual framework, it's possible to understand the impacts of small scale fisheries and aquaculture as shown in the following conceptual framework. In this regards, fishery and aquaculture could contribute to nutrition through dietary intake and food security of individual and households. 


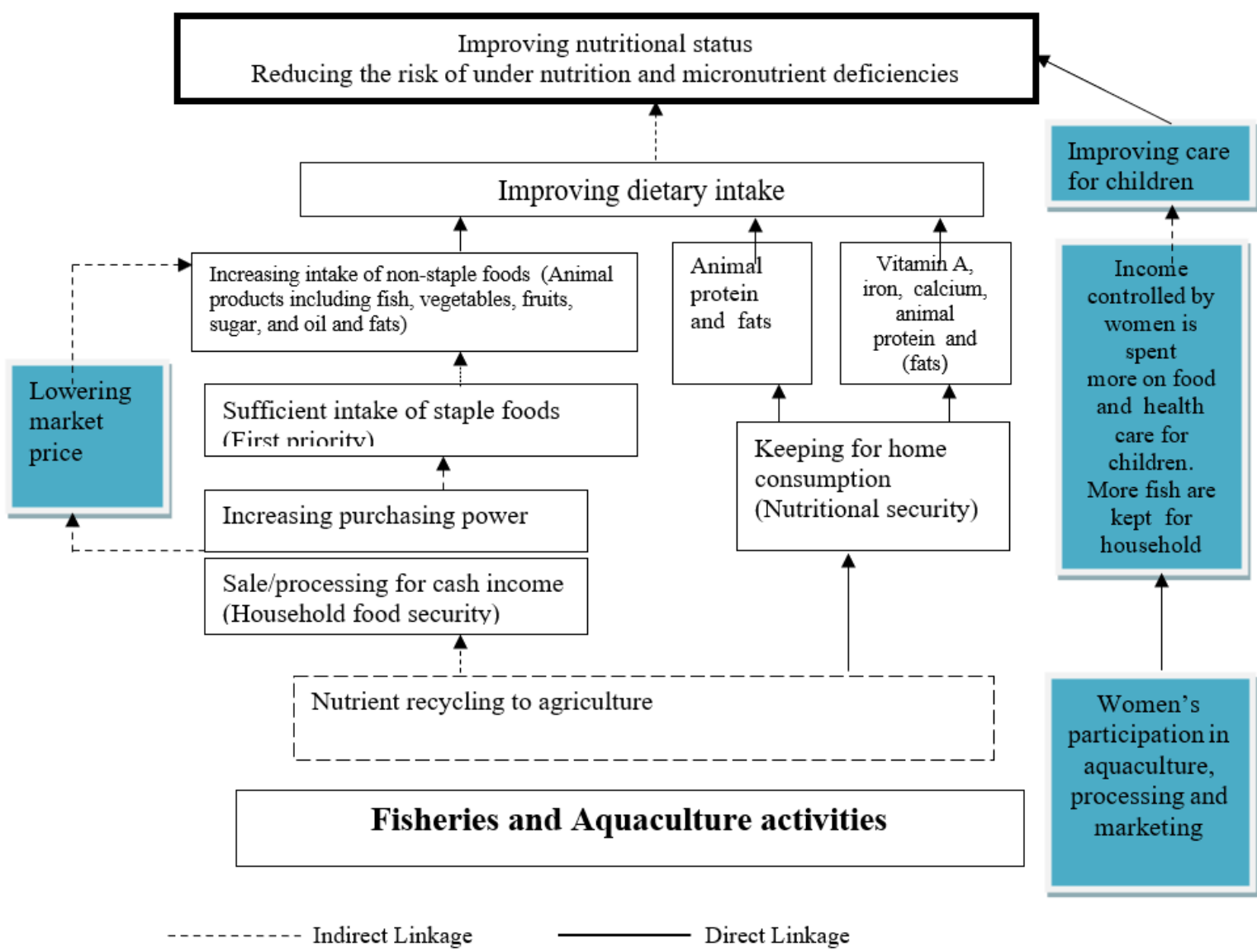

Source: Kawarazuka N. (2010)

Figure 1: The pathways through which aquaculture can contribute to improving nutritional status of the women

Many studies in fishing community do not prioritize about the nutritional status of the fishing community as it is difficult to analyze the nutritional outcome. A study in Laos (Meuschet al., 2003) showed that decreased fish catch resulted in low consumption of fish. As a result high prevalence of malnutrition occurred in the study area and optional capacity building of sustainable aquatic resource management strategies were drawn to improve the current nutritional status of the fisheries community. Another study in Kafue flats, Zambia, found that the relations between low fishing access in the community and household food insecurity and child growth. Fishing activities were a significant and regular practice for the local women to manage with food insecurity, especially during a food scarcity period. High fishing market and increased migrants made it difficult for the locals to engage in fishing, which resulting in increasing vulnerability to food insecurity(GFIES, 2014, Ma'alin et al., 2016, Ayala and Meier, 2017). However, fisheries and under nutrition cannot be simply connected as causal relationship because the nutritional status is determined by many factors and fishing activities are only contribute a small part which can influence to key factors which directly and indirectly relate to nutritional status. Study in Kenya showed the body mass index of lactating mothers from fishing household were found to have a higher body mass index (BMI) compared to non-fish households from fishing households, 11.1\% mothers were underweight, $72.2 \%$ had optimal weight and $13.0 \%$ were over-weight while $3.7 \%$ were obese. For those from non-fishing households, $68.5 \%$ were underweight, $24.1 \%$ had optimal weight and $5.5 \%$ were overweight while $1.9 \%$ were obese(Nguka G et al., 2017).

\section{The Contributions for Food and Nutrition security and existing challenges in Ethiopia}

Fish production and consumption could make the best possible use of underutilized resource presently available to the small farmers to raise their income and also to improve their nutritional status particularly through supply of animal protein and micronutrient requirements. The double burden of malnutrition in Ethiopia can be addressed through linkages of agriculture to nutrition emphasizing food production. In alleviation of these chronic problems for searching for alternative food and income sources and employment opportunities, like fishery sub-sector needs to be given special attention. There must be also an effort towards promotion of agricultural products and fishery for consumption. This effort will be on the ground with evidence based research. In Ethiopia there are many alternative means of achieving food and nutrition security in particular and poverty reduction. Despite the presence of lakes, rivers and reservoirs potential opportunity to produce fish, its 
consumption is insignificant and found to play little role in the households' livelihood. Therefore it is very true to say fisheries and aquaculture in Ethiopia remains more potential than in actual practice, despite the fact that the country's environmental and socio-economic conditions support its development (FAO, 2005). The consumption and demand for fish as a cheap source of protein is on the increase in Ethiopia. But the fish supply in most cases comes from the major lakes and rivers in the country. Like other sub-saharan African countries, fisheries from natural water bodies have failed to meet the ever growing demand for fish. (Moehl et al., 2005). Despite the country's huge aquaculture potential, the contribution of aquaculture towards food and nutrition security is insignificant (Ministry of Agriculture annual report, 2008). Therefore, the importance of aquaculture development for poverty mitigation and food self-sufficiency in the country could not be over emphasized (Kassahun, 2012).

Mainly fresh fish is produced in the Great Rift Valley lakes and in some other northern parts of the country. Price wise, fish is relatively expensive compared with the local prices of vegetables and grains on a unit weight basis, but it is frequently less costly than alternative animal protein sources. With increased marketing efforts and increase in supply, the demand for the fish product could be tremendously increased from the current level. The demand for fish is higher than supply especially in Ethiopian fasting season. This is because of religious influences on consumption patterns; the demand for fish is only seasonal. During lent, Christians who abstain from eating meat, milk, and eggs consume fish, since fish is the substitute of meat (Assefa, 2013). Additionally, fish consumption per year is very low (OECD-FAO, 2011). The national food consumption survey of Ethiopia (2013) indicated that the food group contributing to the highest proportion of women's diet was cereals or grains. Flesh foods including fish consumption was again very low for women in all regions. In the SNNP region, the consumption of this food group $0.4 \%$ in relation to the other food groups. On the other hand, it was reported that only $2.6 \%$ of pregnant women consumed fish in Wondo Genet districts of Sidama zone (Desalegn K., 2011). Even though the demand for fish in the country is increasing, the supply side is not increasing with large opportunities to produce. As mentioned, the potential productions in Ethiopia are major lakes, reservoirs, dams, small water bodies and rivers.

Ethiopia is endowed with many lakes and reservoirs for fish productions. The environmental conditions are very conducive fishery and aquaculture. Therefore, as a means of achieving food and nutrition security and poverty reduction it is important to invest on it. However, the fishery sector has challenges related to existing climate changes, mismanagement fishery resources, lack of timely policies and institution and other technical backups (Kebede et al, 2017). There are numerous explanations ascribing to the low and poor production due to inappropriate and not advancing fishing methods, economic disabilities related to infrastructures like preservation technologies. The existing rules and regulations are not tight as required. The absence of appropriate managements has been affecting the utilization of fishery resources (Lemma Abera Hirpo, 2017). Fish consumption pattern and demand is increasing in Ethiopia. However, in 2016-year Ethiopia produced a total of 45,610 tones (i,e only $0.58 \%$ of total production in Sub-Saharan African countries) (Alemayehu and Tamiru, 2019). Despite the existing challenges fishery has been providing multiple ranges of positive contributions for food and nutrition security. Individuals and households relying on fish production earn income which could directly linked with household assets (Dagninet Amare, 2018). Additionally, the study done in Hawassa, Ethiopia indicated that reproductive age women from fishing households had better fish consumption; household food security and minimum dietary diversity. This shows that fishing contributed to food and nutrition security (Samrawit et al, 2020).

\section{Conclusions and Recommendations}

In many low-income countries with water and fisheries resources, fish is important for livelihoods, income and as food for the rural poor who suffer disproportionately from under nutrition, including micronutrient deficiencies. In alleviation of chronic nutrition problems for searching for alternative food and income sources and employment opportunities, like fishery sub-sector needs to be given special attention. The contribution of fish to household food and nutrition security depends upon availability and access. Ethiopia, the landlocked country, mainly gets fish Great Rift Valley lakes and in some other northern parts of the country. Fish production plays insignificant and little role in the households' livelihood. The supply side does not much with the existing demands. The total fish production of the country accounts only $0.58 \%$ of total production in SubSaharan African countries. Thus fishery is contributing a little due to existing challenges related to production. The challenges are related to existing climate changes, mismanagement fishery resources, lack of timely policies and institution and other technical backups related to loose rules and regulations. Thus, to exploit the maximum contribution of fishery and aquaculture special attentions has to be given Ethiopia.

\section{Reference}

Ahmed, M., and M. H. Lorica (2002). Improving developing country food security through aquaculture development—-lessons from Asia. Food Policy 27:125-141. 
Aiga H, Matsuoka S, Kuroiwa C, Yamamoto S (2009) Malnutrition among children in rural Malawian fishfarming households. Trans R Soc Trop Med Hyg 103:827-833

Alemayehu Abebe Wake and Tamiru Chalchisa Geleto (2019). Socio-economic importance of Fish production and consumption status in Ethiopia: A review. International Journal of Fisheries and Aquatic Studies 2019; 7(4): 206-211

Amare D, Endalew M, Debas T, Demissew A, Temesgen K, et al. (2018) Fishing Condition and Fishers Income: The case of Lake Tana, Ethiopia. Int J Aquac Fish Sci 4(1): 006-009. DOI: http://doi.org/10.17352/24558400.000035 .

and the Pacific, Bangkok, Thailand, Publication No. 2003/11. 34 pp..

Assefa Mitike Janko(2013). Assessment of fish products demand in some water bodies of Oromia, Ethiopia. International Journal of Agricultural Sciences ISSN: 2167-0447 Vol. 3 (8), pp. 628-632, October, 2013. Available online at www.internationalscholarsjournals.org (C) International Scholars Journal.

Béné, C., G. Macfadayen, and E.H. Allison (2007). Increasing the contribution of small-scale fisheries to poverty alleviation and food security. Fisheries and Aquaculture Technical Papers 481, FAO, Rome, 141 pp.

Desalegn Kuche(2011) Nutritional Status, Dietary Practices and Associated Factors of Pregnant Women in Wondo Genet District, Sidama Zone,Southern Ethiopia. M.Sc Thesis, Hawassa University, Hawassa, Ethiopia

Dey MM, Kambewa M, Prein D, Jamu FJ, Paraguas E, Pemsl E, Briones M (2006) Impact of development and dissemination of integrated aquaculture-agriculture (IAA) technologies in Malawi. NAGA World Fish Centre Quarterly 29(1 \& 2):28-35

Ethiopian Public Health Institute (EPHI) (2013), http://www.ephi.gov.et. Ethiopia National Food Consumption Survey Addis Ababa, Ethiopia

FAO (2006): State of world aquaculture 2006. FAO Fisheries Technical Paper 500, Rome, Italy

FAO 2013. The State of Food and Agriculture. Innovative food systems. Rome, FAO.

FAO. (2009 b). Low - income food - deficit countries 2009. [Online] FAO country profiles. Available at: http://www.fao.org/countryprofiles/lifdc.asp.

FAO. 2012. The State of World Fisheries and Aquaculture. Rome, 82-86 pp.

Food and agriculture organization of the United Nations (FAO) and world fish center, small-scale capture fisheries- a global overview with emphasis on developing countries a preliminary report of the big numbers project, 2008.

Gebremedhin, S., Budusa, M., Mingist, M. and Vijverberg, J. Determining factors for fishers' income: the case of lake Tana, Ethiopia International Journal of Current Research Vol. 5, Issue, 5, pp.1182-1186,

IFPRI (International Food Policy Research Institute). 2014a. Global Nutrition Report 2014: Actions and Accountability to Accelerate the World's Progress on Nutrition. Washington, DC.

Jahan, K. M., Ahmed,M., Belton, B. (2009). The impacts of aquaculture development on food security: lessons from Bangladesh. Aquac Res, 1-15

Kassahun Asaminew Desta(2012). Utilization of locally available feedstuffs for small-scale aquaculture production in Ethiopia. Ph.D. Thesis, University of Natural Resources and Life Sciences Vienna

Kawarazuka N (2010) The contribution of fish intake, aquaculture, and small-scale fisheries to improving nutrition: a literature review. Working Paper No.2106. The WorldFish Center, Penang, Malaysia. $54 \mathrm{p}$

Kebede A, Meko T, Hussein A, Tamiru Y (2017) BReview on Opportunities and Constraints of Fishery in Ethiopia. Int J Poul Fish Sci .1(1):1-8. DOI: 10.15226/2578-1898/1/1/00104

Kumar P, Dey MM (2006) Nutritional Intake and Dynamics of Undernourishment of Farm Households in Rural India. Indian Dev Rev 4(2):269-284

Lemma Abera Hirpo(2017). Fisheries production system scenario in Ethiopia. International Journal of Fisheries and Aquatic Studies 2017; 5(1): 79-84

Malcolm Beveridge, Michael Phillips, Shakuntala Haraksingh Thilsted, Marc Metian.(2013). Meeting the food and nutrition needs of the poor: The role of fish and the opportunities and challenges emerging from the rise of aquaculturea. Journal of Fish Biology. 83, 1067-108.

Manasi, S., Latha, N. and Raju, K.V. 2009. Fisheries and livelihoods in Tungabhadra Basin, India: Current status and future possibilities. Working Paper 217, the Institute for Social and Economic Change, Bangalore, 24 pp.

Meusch E., Yhoung-Aree J., Friend R., Funge-Smith S.J. 2003. The role and nutritional value of aquatic resources in

MoARD, (2008). Ethiopian Ministry of Agriculture and rural development annual report

Moehl, J., Halwart, M., 2005. A synthesis of the formulated animal and aquafeed industry in sub-Saharan Africa. CIFA Occasional Paper 26, Food and Agriculture Organization of the United Nations, Rome.

OECD and FAO Secretariats (2011). Agricultural outlook 2011-2020 Accessed at http://dx.doi.org/10.1787/888932428253 (Accessed on December 28,2015) 
Pachón H, Simondon KB, Fall ST, Menon P, Ruel MT, Hotz C, Creed- Kanashiro H, Arce B, Dominguez MRL, Frongillo EA, Brown DL (2007) Constraints on the delivery of animal-source foods to infants and young children: Case studies from five countries. Food Nutr Bull 28(2):215-229

Samrawit Yilma, Heidi Busse, Derese Tamiru Desta, Fikadu Reta Alemayehu (2020). Fish consumption, dietary diversity and nutritional status of reproductive age women of fishing and non-fishing households Hawassa, Ethiopia: Comparative cross sectional study. M.Sc. Thesis.

Speedy, A.W. (2003). Animal Source Foods to Improve Micronutrient Nutrition in Developing Countries, Journal of Nutrition, 133:40485-40535.

the livelihoods of rural people - a participatory assessment in Attapeu Province, Lao PDR. FAO Regional Office Asia

Thompson, B. \& Subasinghe, R. 2011. Aquaculture's role in improving food and nutrition security.150-162p. In B. Thompson \& L. Amoroso, eds. Combating micronutrient deficiencies. Rome, FAO.

UNDP (2010) What Will It Take to Achieve the Millennium Development Goals? - An International Assessment, United Nations Development Programme One, United Nations Plaza, New York, NY 10017, USA

UNICEF (1990) Strategy for Improved Nutrition of Children and Women in Developing Countries. UNICEF, New York.

USDA (2005), Nutrient Data Laboratory. USDA-nutrient data home.(Last updated:18 November, 2005) http://fnic.nal.usda.gov/nal_display/index.php?info_center=4\&tax_level=2\&tax_ subject=279\&topic_id=1387.(Accessed on December 28, 2015)

WHO (2007) Protein and amino acid requirements in human nutrition. World Health Organization, Geneva

WHO (World Health Organization ) (2015m). “Micronutrient Deficiencies.” 2015. www.who.int/nutrition/topics/ida/en/. (Accessed November 15,2015) 